\title{
BIM PARA COORDENAÇÃO ESPACIAL: REVISÃO BIBLIOGRÁFICA E FERRAMENTAS
}

\author{
Karina Coelho $^{(1)}$, Bruna Murbach ${ }^{(2)}$ \\ (1) Escola Politécnica - Universidade de São Paulo, São Paulo \\ (2) Instituto Federal de Educação, Ciência e Tecnologia de São Paulo, São Paulo
}

\begin{abstract}
Resumo
A coordenação espacial é uma atividade que apesar de crítica e desafiadora que garante que o projeto atenda aos requisitos econômicos, estéticos e funcionais. Apesar dos custos da coordenação de projeto serem signficativos, $57 \%$ dos potenciais erros de projeto têm um impacto direto nos custos da construção. Estudos demonstram que o BIM tem importante impacto no processo de coordenação, proporcionando às equipes de trabalho menos tempo para resolver interferências nos projetos. Um dos desafios de um projeto colaborativo BIM é determinar como conectar os diversos modelos e como os agentes envolvidos se organizam para interagir de forma colaborativa. As condições para o desenvolvimento das interações dependem das possibilidades de funcionalidades que as ferramentas apresentam. Além das ferramentas tradicionais, ao longo dos últimos anos, as ferramentas baseadas na nuvem têm sido amplamente desenvolvidas com o propósito de aprimorar o processo colaborativo BIM.

Este artigo objetiva avaliar as funcionalidades de algumas ferramentas para coordenação espacial por meio de dois estudos de caso e avaliar o suporte que cada uma pode oferecer à coordenação do projeto durante seu desenvolvimento.
\end{abstract}

\section{Introdução}

A coordenação de projetos é uma atividade que visa garantir que os projetos atendam aos requisitos econômicos, estéticos e funcionais estabelecidos. Esse processo permite que a equipe detecte potenciais conflitos antes de se tornarem problemas durante a obra. Alguns estudos estimam que $57 \%$ dos erros de coordenação de projeto têm um impacto direto nos custos da construção [1].

Durante o processo de projeto, a informação é filtrada, idealizada e transformada em ciclos sucessivos de interações, em que os modelos individuais são mesclados, interferências detectadas, novas informações agregadas e novos problemas percebidos [2].

$\mathrm{O}$ processo de projeto consiste tipicamente em passos inteconectados: identificação do problema, resolução do problema e documentação do problema. $\mathrm{Na}$ identificação dos problemas, a quantidade de informações aumenta gradativamente e pode ter início um grande 
caos na comunicação. São necessárias várias pessoas para rastrear informações e garantir que perdurem durante o projeto até que os problemas sejam solucionados. [3]

Uma das promessas do BIM é a melhoria no processo de coordenação de projeto, apesar de também ter se mostrado um processo desafiador devido à grande quantidade de possibilidades tecnológicas. O desenvolvimento de projetos BIM envolve, comumente, diferentes e diversos agentes e organizações, sendo que apenas partes dos processos ocorrem dentro de uma mesma empresa. Essa é uma das características inexoráveis da indústria da construção civil, e não uma exclusividade do uso do BIM. [4].Com o BIM as informações são compartilhadas em diferentes formatos, programas de software e locais, tornando difícil obtê-las de forma precisa e ágil.

\section{Evolução na Coordenação Digital}

Alguns estudos demonstram que o BIM tem importante impacto no processo de coordenação, possibilitando a resolução mais rápida de interferências nos projetos. Um dos desafios de um projeto colaborativo BIM é determinar como conectar os diversos modelos e como os agentes envolvidos devem se organizar para interagir de forma colaborativa [5]

O processo de desenvolvimento de um projeto é cíclico e interativo, e no caso do BIM envolve a coordenação do processo de projeto e a coordenação do desenvolvimento do modelo que ocorrem de maneira simultânea. Dessa forma, a geração dos modelos é uma tarefa complexa: demanda esforços conjuntos e integrados por meio da gestão de projeto - o qual o modelo deve refletir em suas diferentes fases de evolução - e do produto - do nível de complexidade e fidelidade do próprio modelo com a realidade. [10]

Souza [6] afirma a importância do Gestor do Processo para atuar como facilitador da operacionalização das tecnologias que permeiam o BIM a favor dos objetivos estratégicos do empreendimento. Para a autora também é sua responsabilidade operacionalizar a Colaboração por meio de processos claros e fluidos para a comunicação, definição clara de responsabilidades e organização de informações. A operacionalização da colaboração tem sido desenvolvida de distintas maneiras e vem evoluindo no processo BIM, como pode ser visto na figura abaixo em que são elucidadas as possíveis ferramentas adotadas na Coordenação Digital.

\section{A Evolução da Coordenação Digital}

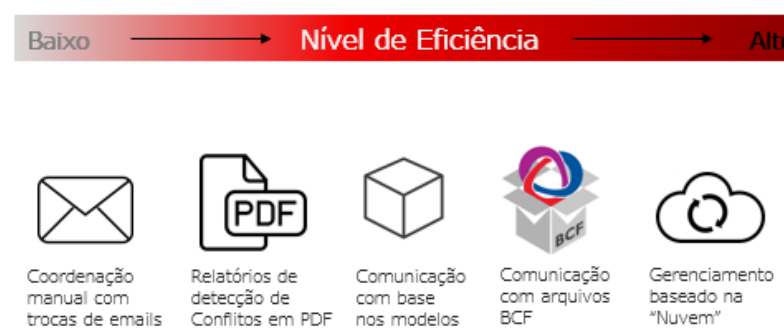

Figura 1: A evolução da Coordenação Digital. Adaptado de [2].

A coordenação das informações realizada por meio da troca de emails é um método de colaboração inadequado, pois resulta em várias versões das informações enviadas às diferentes partes interessadas. As questões levantadas se perdem em vários emails, resultando em comunicações duplicadas e dificuldade de rastreabilidade sobre o status de um problema. 
Com o objetivo de resolver a falta de rastreabilidade de informações, passou-se à elaboracão de relatórios de detectação de conflitos, normalmente enviados em formato .pdf. Os modelos são produzidos mas o acesso às interferências apontadas se dá por meio de imagens dos relatórios, tal qual o da figura 2. Embora as interferências identificadas se tornem mais compreensiveis pela visualização $3 \mathrm{D}$, tal prática, por outro lado, causa dificuldades à equipe quanto à localização e compreensão das questões apontadas uma vez que muitos projetistas ainda incorporam a resolução desses problemas às representações $2 \mathrm{D}$ de seus projetos.

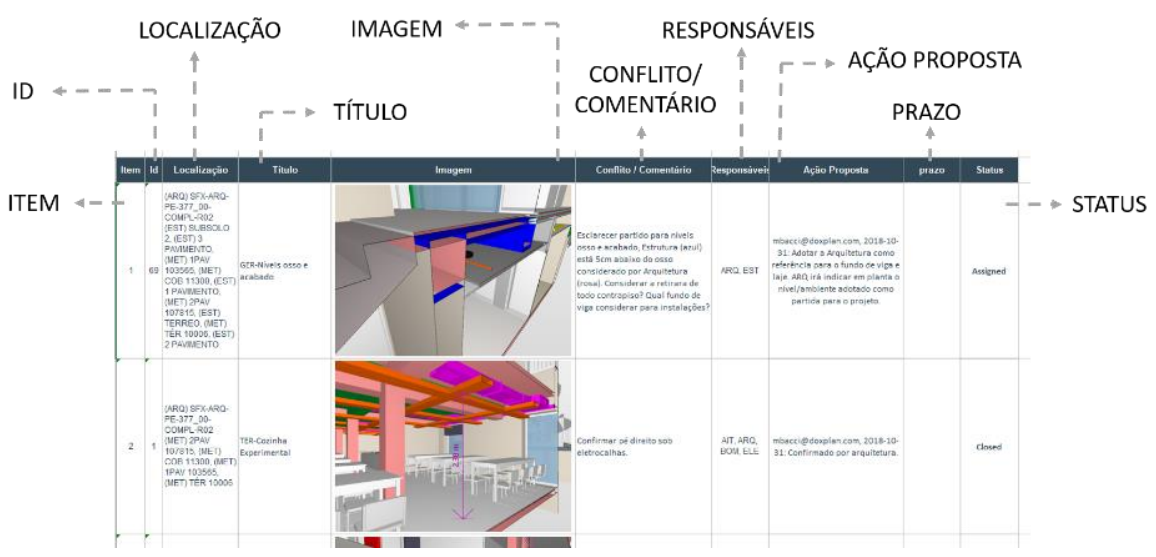

Figura 2: Relatórios de Projeto em PDF.

A troca de modelos, por meio de respositórios de arquivos, se mostrou como uma possível maneira de resolver a dificuldade de identificação dos problemas, de modo a se obter a visão completa do empreendimento. O compartilhamento de Modelos Autorais, que deveriam ser de uso exclusivo do projetista, são compartilhados com toda a equipe. Encontra-se nesse processo dificuldades operacionais uma vez que o modelo autoral vem carregado de informações de teor gráfico e numérico as quais prejudicam o desempenho dos sistemas. [7]. A criação de um modelo federado que possa ser compartilhado é um outro método de trabalho. Este é obtido pela agregação dos modelos de modo coordenado, em softwares autorias ou não autorais, sendo mais comum a coordenação utilizar ferramentas não autorais, demandando uso de arquivos no formato ifc. A partir da criação do modelo federado um arquivo é compartilhado com a equipe e pode ser utilizado para visualização de itens de incompatibilidade previamente apontados. Esses dois cenários pressupõem uma frequência de uploads e downloads sob a responsabildade da coordenação dos projetos.

Com o objetivo de ser um padrão aberto, capaz de garantir fluxos de comunicação entre os diferentes softwares BIM, o padrão BCF foi um formato de comunicação criado pela Building Smart International. É um arquivo comprimido que prevê uma pasta para cada interferência detectada. [11]. Nesta pasta existem três tipos de arquivos responsáveis pela transmissão de todas as informações úteis para definir o problema detectado. Esses arquivos são os Markups (informações textuais), Viewpoints (pontos de vista que enquadram o problema detectado) e Snapshots (imagens ligadas aos pontos de vista do modelo original). Existem duas opções de processo para intercâmbio e utilização do BCF: a primeira opção é a utilização de arquivos BCF nativos, que precisam de uma troca sucessiva de arquivos, sendo necessária uma gestão meticulosa de versões e a segunda é a utilização de uma plataforma de colaboração em nuvem, com integração automática do BCF. 
Nos últimos anos, as ferramentas baseadas na nuvem têm sido amplamente desenvolvidas com o propósito de aprimorar o processo colaborativo BIM. Os servidores de modelos BIM são definidos como um conjunto de bancos de dados relacionais e centrais que funcionam como repositórios de informações e permitem que outras aplicações possam atualizar seus modelos, importar informações de modelos de outras especialidades e gerar vistas de dados a partir de combinações de modelos. [8]

Esses servidores têm por objetivo possibilitar a comunicação e a colaboração e essa capacidade de integração possibilita a criação de uma fonte unificada viabilizando o trabalho de forma integrada, e não apenas colaborativa.

\section{Ferramentas}

As diferentes ferramentas para coordenação digital têm distintos potenciais e devem se adequar aos processos das empresas bem como à maturidade de suas equipes e ao uso pretendido dos modelos. As condições para o desenvolvimento das interações também dependem das possibilidades de funcionalidades que as ferramentas apresentam para preparação, inspeção, anotação, visualização, navegação e registros dos modelos. [3]

$\mathrm{Na}$ tabela 01 foram avaliadas as funcionalidades de ferramentas de modelos autorais e não autorias (adaptada de [3]). Não foram consideradas as avaliações de modelos a partir dos softwares de design por não se considerar como um fluxo adequado de trabalho à gestão de projeto. Acredita-se que o fluxo de trabalho otimizado possibilitado pelos padrões abertos pode minimizar o desperdício de tempo durante todo o cronograma do projeto e aumentar sua eficiência.

Para a coordenação digital é importante que as ferramentas sejam capazes de armazenar os problemas, mas também gerenciá-los ao longo do tempo, definindo o tipo de problema (conflito, deficiência de dados, método de modelagem), atribuindo metadados sobre um problema (local, prioridade e data levantada), mudança de status de um problema, gerenciamento de comentários de diferentes partes interessadas e definição de responsabilidades. É tarefa do coordenador manter todas as informações acima intactas à medida que o modelo é desenvolvido e acessível a toda a equipe do projeto, independentemente de sua experiência ou plataforma usada.

Percebe-se que ao longo dos últimos anos, as ferramentas baseadas na nuvem têm sido amplamente desenvolvidas com o propósito de aprimorar o processo colaborativo BIM pois são capazes de garantir um fluxo de trabalho mais consistente e que atende com maior eficácia as demandas citadas acima. 
Tabela 1: Funcionalidades de ferramentas de coordenação digital Adaptada de [3] [9]

\begin{tabular}{|c|c|c|c|c|c|c|c|c|c|}
\hline FUNCIONALIDADES & $\sum_{n}^{8}$ & 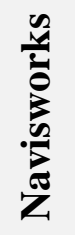 & 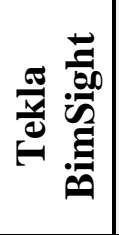 & है & $\sum_{0}^{\frac{0}{\sigma}}$ & 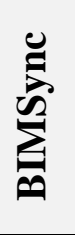 & 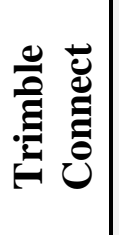 & $\sum_{\infty}$ & 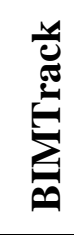 \\
\hline \multicolumn{10}{|l|}{ Salvar e carregar vistas } \\
\hline \multicolumn{10}{|l|}{ Agrupar vistas juntas } \\
\hline \multicolumn{10}{|l|}{ Acesso simultâneo ao 2D e 3D } \\
\hline \multicolumn{10}{|l|}{ Anexar 2D a outros meios de design 2D } \\
\hline \multicolumn{10}{|l|}{ Pan/Arrastar } \\
\hline \multicolumn{10}{|l|}{ Zoom } \\
\hline \multicolumn{10}{|l|}{ Rotacionar } \\
\hline \multicolumn{10}{|l|}{ Medição } \\
\hline \multicolumn{10}{|l|}{ Modificação de modelo } \\
\hline \multicolumn{10}{|l|}{ Sistema de eixos } \\
\hline \multicolumn{10}{|l|}{ Detecção de conflitos } \\
\hline \multicolumn{10}{|l|}{ Comparação de modelos } \\
\hline \multicolumn{10}{|l|}{ Código de cores } \\
\hline \multicolumn{10}{|l|}{ Esconder/ reexibir componentes } \\
\hline \multicolumn{10}{|l|}{ Comentar } \\
\hline \multicolumn{10}{|l|}{ Anotar } \\
\hline \multicolumn{10}{|l|}{ Grifar } \\
\hline \multicolumn{10}{|l|}{ Registro de alterações } \\
\hline \multicolumn{10}{|l|}{ Registro de problemas de projeto } \\
\hline \multicolumn{10}{|l|}{ Upload/ download de modelo } \\
\hline \multicolumn{10}{|l|}{ Mescla de modelos } \\
\hline \multicolumn{10}{|l|}{ Acesso ao modelo em nuvem } \\
\hline \multicolumn{10}{|l|}{ Hardware e banda larga dedicados } \\
\hline \multicolumn{10}{|l|}{ Acompanhamento do modelo } \\
\hline Suporte a múltiplos formatos de modelo & & & & & & & & & \\
\hline
\end{tabular}




\section{Estudos de Caso}

\subsection{Estudo de caso 1}

Trata-se do projeto de retrofit de um edifício educacional, com aproximadamente $12.000 \mathrm{~m}^{2}$. Parte de sua fachada é tombada pelo patrimônio histórico. As atividades escolares permaneceriam em funcionamento durante as obras, trazendo a necessidade de seu faseamento e agregando complexidade à gestão dos projetos, como visto na figura 3.
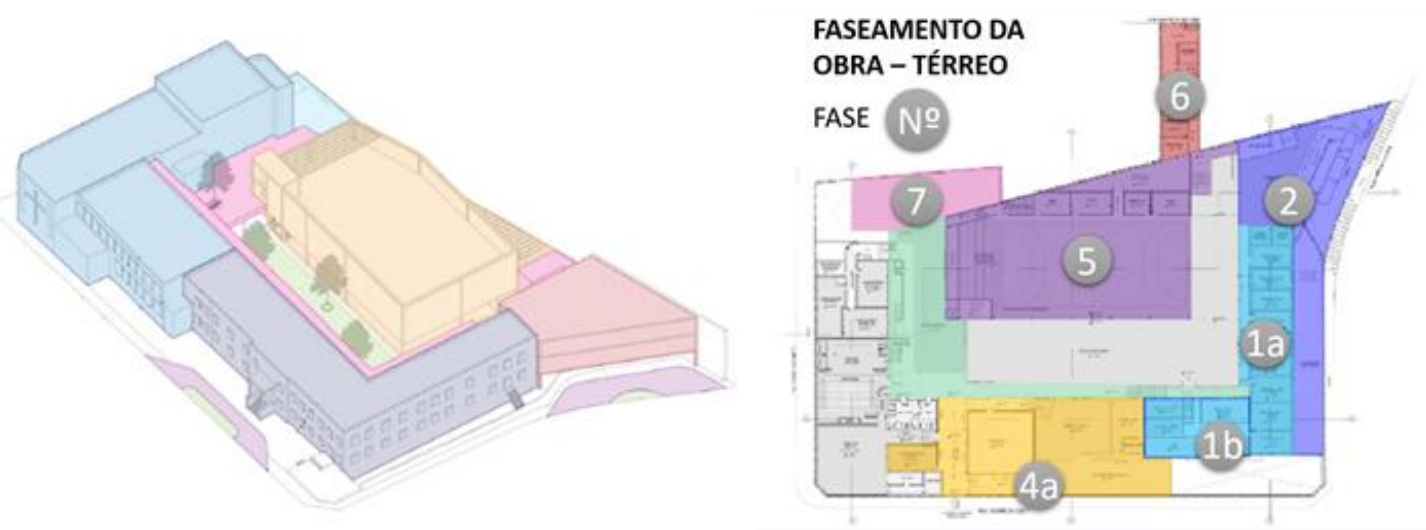

Figura 3: Estudo Preliminar de Arquitetura e Faseamento da Obra.

O uso de softwares BIM se deu na fase de anteprojeto, logo após a aprovação do cliente para o Estudo Preliminar de Arquitetura. Nessa fase inicial, o próprio escritório de arquitetura realizou o papel de gestor do processo de projeto, sendo responsável pela contratação da equipe de projetos e definição de premissas de projeto (junto ao cliente) e de modelagem.

A questão da contratação dos projetos abriu margens para contratempos posteriores, já desde o início, uma vez que foram exigidos projetos de sistemas prediais com contratos de modelagem que comtemplavam apenas duas revisões dos modelos e seu uso exclusivo para a compatibilização de projetos. Seriam utilizados dois softwares de modelagem: Revit e DDS$\mathrm{CAD}$, os quais exigiriam esforços na operacionalização das trocas de arquivos e registros de informações.

Ao longo do processo uma ordem complexa de contratempos levou a equipe à realização de diversas revisões de projeto para as quais os projetistas, não tinham exigências contratuais para revisão de modelagem. Todo processo de desenvolvimento de projetos (com exceção do projeto de arquitetura) ocorreu em ferramentas $\mathrm{CAD}$, sendo posteriormente modelado, pelo próprio projetista. Nesse ponto já foi possível perceber uma deficiência no compasso das atividades, sendo necessária a intervenção do Gestor de Projetos (empresa de arquitetura), observando a sequência e precedência de atividades de projeto e modelagem, dadas as características especiais de contratação BIM.

Durante a fase de anteprojeto, a ferramenta de coordenação digital utilizada foi o Tekla BIM Sight. A equipe de arquitetura conduziu as reuniões utilizando-a amplamente para a visualização de incompatiblidades de projeto, facilitando a identificação e resolução dos problemas. Foi percebida também a facilidade de compreensão das soluções de projeto por parte do cliente com a interface da ferramenta, visualizada na Figura 4. 

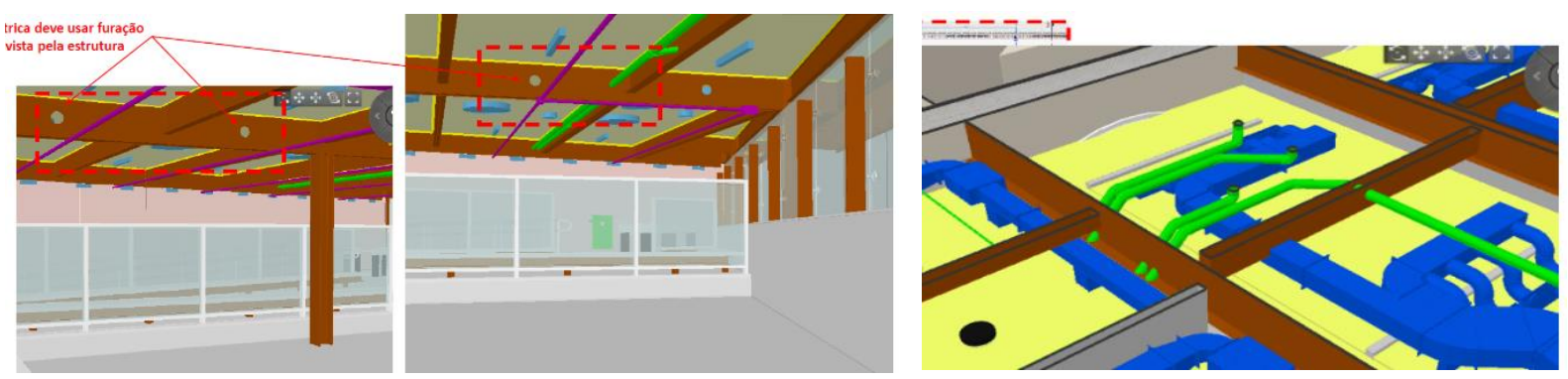

Figura 4: Relatório em PDF, com imagens do Tekla BIM Sight. Fonte: Autoras.

A partir da fase seguinte, uma empresa externa de Gestão de Projetos e Obras foi contratada pelo cliente, assumindo integralmente as funções de coordenação dos projetos, em substituição à empresa de arquitetura. Essa passagem de responsabilidade aconteceu de maneira informal, sem que a nova empresa tomasse ciência completa das premissas de contratação dos projetos, em especial dos fluxos BIM. Pôde-se observar então a quebra na fluidez das informações de projeto, registradas até o momento por emails e documentos em formato .pdf. Apesar do Tekla BIM Sight permitir a troca de informações em formato BCF, não houve sua utilização, demonstrando uma falta de conhecimento na aplicabilidade deste padrão de arquivo.

Tal empresa iniciou seu processo de trabalho utilizando uma nova ferramenta de coordenação, o Solibri. Percebeu-se já neste primeiro momento a falta de gestão do processo de modelagem: até este estágio a empresa de arquitetura permanecia responsável pela modelagem das peças estruturais, a despeito da contratação da empresa de estrutura exigir a entrega de arquivos em formato ifc. cujo uso, anteriormente, pode ser visto na figura abaixo.
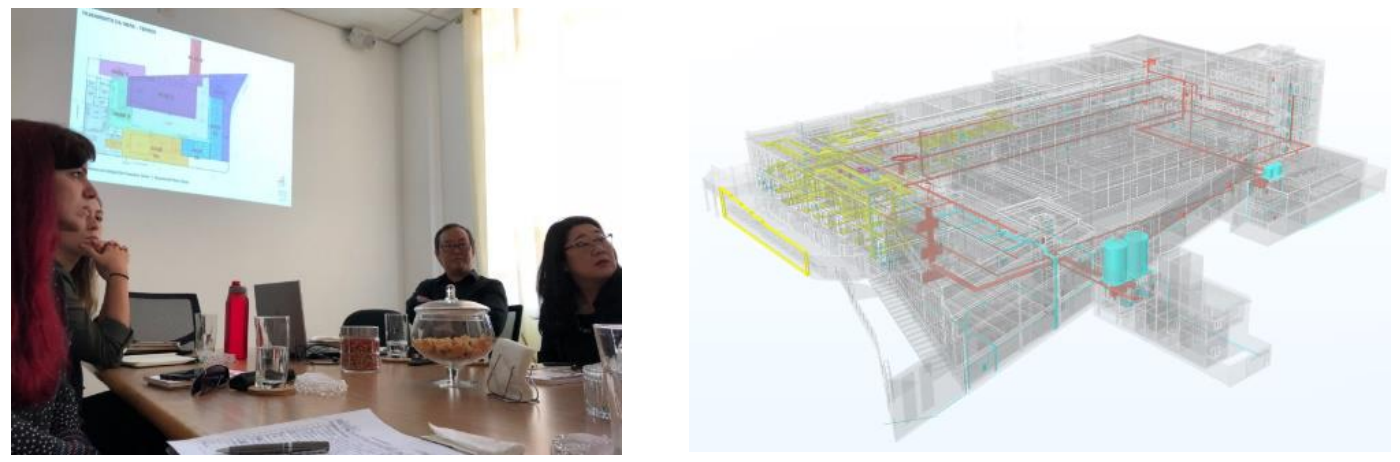

Figura 5: Reunião de projeto e Modelos de Sistemas.

Com a entrega do modelo de estrututa, feita pelo projetista, foram encontradas as primeiras discrepâncias entre arquitetura e estrutura, com falta de definições coerentes entre níveis osso e acabado para todos os pavimentos. Tratando-se de um edifício existente, as limitações de espaço de entreforro - já que prevalecia um PD baixo e sem padronização - resultou em inúmeros conflitos entre dutos de ar condicionado, eletrocalhas e tubulações. Cada conflito foi tratado caso a caso.

Não obstante vale salientar que apesar de não aproveitada em sua completude, a modelagem BIM ao menos da disciplina de arquitetura, estrutura e inicialmente dos sistemas prediais levou à percepção não apenas de conflitos existentes entre as disciplinas, mas de novas soluções de projeto que, sem a visualização tridimensional do produto de projeto, não teriam sido 
vislumbradas. Contudo, nesse caso até mesmo a realização do projeto modelado foi apontada pela coordenação do projeto como um fator de atraso da tomada de decisões.

De forma bastante acentuada, uma coordenação de projeto que afirma estar a par das novas tecnologias, mas que acaba por atravancar o processo de projeto com o da obra - evocando a questão de prazos - e evitar o uso pleno das ferramentas de coordenação BIM, abandonadas ao longo do tempo do projeto levou à descrença da efetividade da metodologia e ao processo de projeto e obra conturbados. A questão está então, não apenas na disponibilidade destas ferramentas, mas em seu uso amplo e contínuo durante todas as etapas de projeto e integrando, de fato, todas as disciplinas.

\subsection{Estudo de caso 2}

Trata-se de um edificio comercial composto por uma torre corporativa amalgamada a um volume de teatro e café, num total de 12 pavimentos sobresolo e quatro subsolos com aproximadamente $45.000 \mathrm{~m}^{2}$ apresentando a complexidade advinda deste tipo de empreendimento, observado na figura 6 . O processo de projeto ainda está em andamento e deve se estender até outubro de 2020.
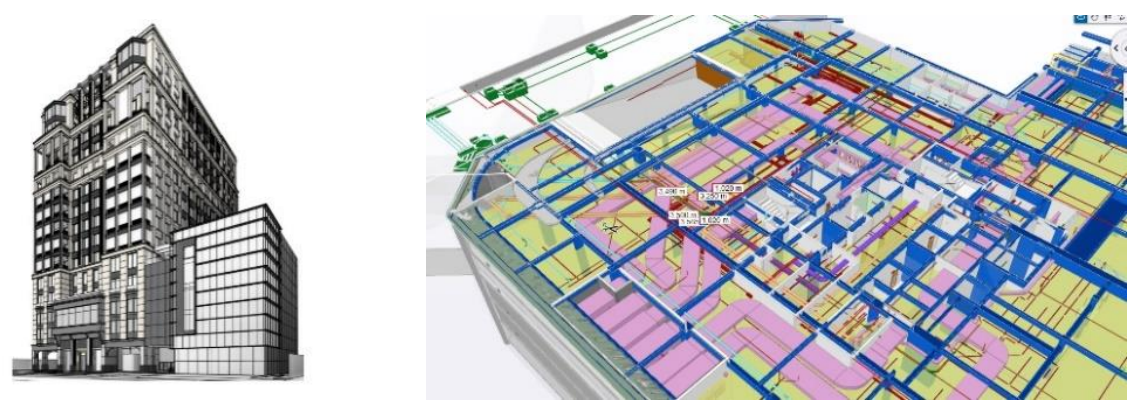

Figura 6: Edificio comercial e seu Pavimento Térreo.

Este empreendimento passou por um longo processo de transformações, incluindo mudanças na área incorporada, as quais implicaram no atraso no processo de projeto e sobreposição com o início das atividades de construção. Em meados de 2019, quando as fundações já estavam em construção, foi iniciado o processo de modelagem e compatibilização BIM do projeto com o intermédio de um escritório especializado (composto pelas autoras do artigo).

Até então a análise e compatibilização dos projetos - que é feita por uma empresa externa - era realizada apenas com os projetos $2 \mathrm{D}$, seguindo a metodologia de anotações nos PDFs. À primeira etapa deste processo apenas alguns projetistas utilizavam modelos BIM. Foi feito o levantamento da condição dos modelos BIM já existentes - notadamente o de arquitetura, estrutura e ar condicionado - e da necessidade de modelagem dos projetos das disciplinas de instalações prediais remanescentes - hidráulica, elétrica e automação - com o fim de possibilitar que todas as disciplinas envolvidas no projeto chegassem ao mesmo patamar de interação.

Já nessa etapa se iniciam os primeiros conflitos no processo de coordenação do empreendimento: por um lado, os projetos que são inicialmente desenvolvidos de forma bidimensional e cuja modelagem é terceirizada levam mais tempo para serem utilizados em interação com os modelos das disciplinas já modeladas. Esse relativo atraso levou a empresa coordenadora a uma análise inicial dos PDFs de projeto e geração de um relatório preliminar de conflitos. 
A compatibilização BIM produziu as primeiras descobertas no processo de coordenação: conflitos inerentes aos próprios projetos, mesmo antes de serem compatibilizados com outras disciplinas, visto que a modelagem 3D leva a análises e questionamentos que muitas vezes são ignorados no desenvolvimento de um projeto $2 \mathrm{D}$, tais quais altura de tubulações, diâmetros de tubulações, interferências entre sistemas diferentes e especificação dos materiais adotados no projeto. Após a modelagem todos os projetos tiveram seus modelos exportados para o formato IFC e inseridos na plataforma online Trimble Connect.

O relatório gerado, embora a princípio tenha levado mais tempo para ser produzido do que o relatório 2D, exemplifica claramente tanto como a metodologia BIM leva à identificação de problemas dificilmente vislumbrados pela compatibilização tradicional como permitiu que, durante as reuniões de coordenação de projeto, com a visualização clara destes problemas, novas soluções fossem mais facilmente e rapidamente engendradas. Logo, o que a princípio gera uma espera maior para a resolução dos conflitos de projeto, na realidade leva a um ganho de tempo, uma vez que, no futuro, não serão despendidos tempo - e dinheiro - para solucionar problemas que não foram visualizados durante o projeto - e que seriam vistos apenas durante a obra - assim como na proposição de soluções mais eficientes.
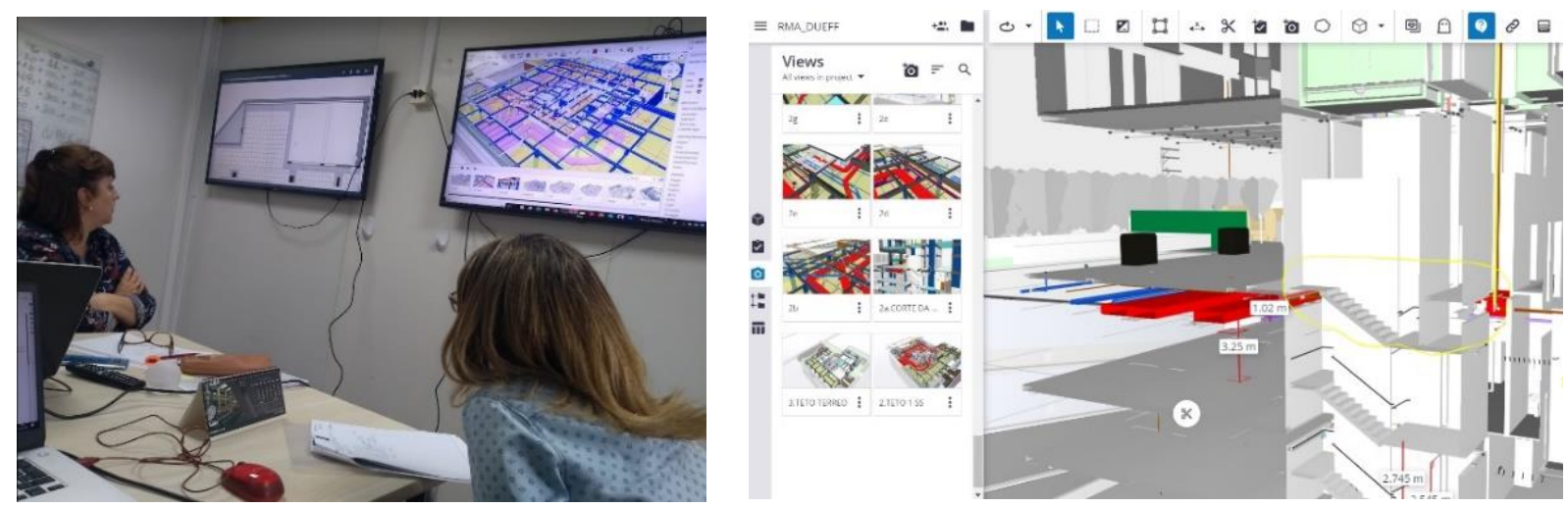

Figura 7: Reunião de projetos e Interface do Trimble Connect.

Após essa resistência inicial, com a apresentação do relatório BIM em reuniões sequenciais, junto as equipes de projeto - exemplificadas na figura 7 - houve uma maior aceitação e até empolgação das equipes - com destaque para a construtora responsável - pelo uso da tecnologia BIM, vislumbrando até o uso dos modelos de projeto na obra. Entretanto, com a continuidade do projeto, e de novas revisões permanecem os desafios da modelagem posterior à emissão dos projetos $2 \mathrm{D}$ e da realização de relatórios posteriores, ainda não integrados às atividades gerais do projeto. Também é suscitada a questão da real utilização dos processos de coordenação integrados: o modelo integrado online foi disponibilizado para todos os stakeholders - de projetistas a coordenadores - já configurado com diversas vistas e markups, entretanto, ainda assim é raramente utilizado para a análise de problemas. Os participantes ainda recorrem aos modelos autorais para a visualização das dificuldades. Vê-se, pois, que a coordenação BIM e seus potenciais apresentam evoluções seguidas de barreiras de difícil dissolução, por estarem mais conectadas à resistência dos agentes envolvidos e a uma coordenação desalinhada com os princípios dessa metodologia, do que com as ferramentas disponíveis.

Neste caso específico, entretanto, a incorporadora e construtora do empreendimento iniciou, a partir da presente experiência, um processo de empenho na compreensão das possibilidades 
trazidas pela metodologia BIM, iniciando um curso de capacitação básico da ferramenta Revit - visando à compreensão das potencialidades desta - assim como de ferramentas específicas para a coordenação de projetos, ampliando seu campo de conhecimento neste quesito.

\section{Considerações Finais}

A análise da evolução das ferramentas de coordenação digital BIM, assim como as experiências acima descritas, evidenciam como para a melhor prática da coordenação BIM e da evolução do projeto à obra, a escolha deve estar em conformidade com o grau de maturidade BIM de toda a equipe de projetos e da equipe de coordenação.

Como visto nos casos apresentados, o BIM mostrou-se bastante relevante para a obtenção de informações mais precisas nas reuniões de coordenação de projetos, trazendo ganhos claros neste processo. No entanto, ao alcance total das possibilidades de melhorias nos processos de gestão com o uso do BIM compete o tratamento do BIM como um processo a parte que necessita, invariavelmente, de gestão especial, que compreenda e se alinhe às necessidades organizacionais desta metodologia, tal qual a contratação de projetos delimitando etapas de modelagem consecutivas às revisões e a coordenação precisa do cronograma de projetos necessários à cada etapa de detalhamento do empreendimento.

Portanto, o despreparo e - em certa medida - irreverência das equipes de coordenação para a relevância e uso das ferramentas BIM implica em sua subutilização, ainda que se tenham demandado esforços das equipes de projeto ou modelagem. Fica claro, pois, que quanto maior a integração das equipes de projeto e coordenação com o uso destas ferramentas maior o aproveitamento - custo e tempo - de seus potenciais.

Quanto aos ganhos financeiros, ainda, destaca-se que dificilmente consegue-se contabilizar benefícios do BIM na compatibilização devido à necessidade de catalogação dos problemas resolvidos durante o processo de projeto. As inconpatibilidades encontradas precisariam ter levantamento de custo se chegassem até a obra, para que os esforços em termos de investimentos no BIM possam ser justificados, de forma concreta, a todos os agentes do ciclo de vida do empreendimento, em especial aos contratantes, disseminando de forma mais incisiva a prática e tornando-a uma obrigatoriedade para as equipes de coordenação.

Em vista disso, é possível notar que a absorção dos benefícios do BIM deve ser feita em pequenos e graduais passos, já que o BIM modifica a gestão dos projetos tanto em termos da concepção do processo pelas equipes de coordenação quanto, de forma mais prática, por implicar na necessidade de previsão de novas atividades em cronograma.

Ainda que a indústria esteja imbuída de novas tecnologias e plataformas para a visualização de conflitos e coordenação de projeto, está também cerceada de resistências no processo de projeto e, por outro lado, de uma falta de afinidade com as tecnologias emergentes, mesmo com plataformas relativamente simplificadas.

Também de forma gradual deve ser levado em conta o alcance da colaboração total, meta que - mesmo com ferramentas em nuvem disponíveis - necessita da capacitação de profissionais no que diz respeito à obtenção dos benefícios iniciais, tal qual a compatibilização de projeto. Por fim, assim, a capacitação de profissionais e a mudança de concepção do processo de coordenação de projetos intrínsecos ao uso das ferramentas BIM deve levar, como observado em casos da prática, a um maior e gradativo colhimento dos benefícios e potencias desta metodologia e da consequente evolução de suas ferramentas. 


\section{Referências}

[1] Lee, G., Park, H. K., \& Won, J. (2012). D3City project - Economic impact of BIM-assisted design validation. Automation in Construction, 22, 577-586. https://doi.org/10.1016/j.autcon.2011.12.003

[2] L. Manzione, Proposição de uma estrutura conceitual de gestão do processo de projeto colaborativo com o uso do BIM. 2013. 389

[3] S. Mehrbod, "Requirements for Bim based Building Design Coordination Processes" ,Tese (Doutorado), Vancouver, The University of British Columbia, 2018 p. Tese (Doutorado) - São Paulo, Escola Politécnica, Universidade de São Paulo, 2013.

[4] CBIC, "Fundamentos BIM - Parte 1: Implementação do BIM para Construtoras e Incorporadoras”. 1 ed - Câmara Brasileira da Indústria da Construção, Brasília, 2016.

[5] S.Nederveen; R. BEHESHTI, R.; RIDDER, H. DE. Supplier-Driven Integrated Design. Architectural Engineering and Design Management, v. 6, n. 4, p. 241-253, 2010.

[6] F. Souza, Proposição de uma estrutura conceitual de gestão do processo de projeto colaborativo com o uso do BIM. 2013. 389 p. Tese (Doutorado) - São Paulo, Escola Politécnica, Universidade de São Paulo, 2013.

[7] S. Leusin, " Gerencimeamento e Coordenação de Projetos BIM. Um guia de ferramentas e boas prática para o sucesso dos empreendimento". 1 ed.- Elsivier, Rio de Janeiro, 2018

[8] S. Vishal, S.; G, Ning.; W. Xianyu. A theoretical framework of a BIM-based multidisciplinary collaboration platform. Automation in Construction, n.2, p.134-144, 2011.

[9] C.Veillete, "The problem with communication in the AECO industry" in https://bimtrack.co/blog/blog-posts/the-problem-with-communication-in-the-aecoindustry ,2015

[10]C. Veillete, "From confusion to collaboration: my joourney through the evolution of BIM coordination" in https://bimtrack.co/blog/blog-posts/from-confusion-to-collaboration-myjourney-through-the-evolution-of-bim-coordination ,2019

[11]G. Martini, "Fluxo de informação colaborativa em BIM: a importancia do BCF" in https://www.gmarquiteturaengenharia.com/single-post/2019/04/16/Fluxo-deinformaC3A7C3A3o-colaborativa-em-BIM-A-importC3A2ncia-do-BCF ,2019 